\title{
STUDY ON SOME PROPERTIES AND MORPHOLOGY OF COMPOSITES BASED ON POLYETHYLENE GRAFTED ACRYLIC ACID/ETHYLENE-VINYL ACETATE COPOLYMER/CALCIUM CARBONATE
}

\author{
Thai Hoang* and Do Van Cong \\ Institute for Tropical Technology, Vietnamese Academy of Science and Technology, \\ 18 - Hoang Quoc Viet Rd., Cau Giay Dist., Hanoi, Vietnam
}

Received 30 June 2006

\begin{abstract}
Composites based on polyethylene grafted acrylic acid (PE-g-AAc)/ethylene-co-vinylacetate copolymer (EVA)/calcium carbonate $\left(\mathrm{CaCO}_{3}\right)$ were prepared by melt mixing. Relative melt viscosity, morphology, mechanical properties and thermostability of the composites were studied. The experimental results show that the presence of $\left(\mathrm{CaCO}_{3}\right)$ activated by stearic acid (10 - $20 \mathrm{wt} . \%)$ changes lightly stable torque of polymer blend of PE-g-AAc/EVA. Use of modified PE improves compatibility of PE and EVA as well as makes the components disperse into each other better than in blends using unmodified PE. Tensile strength and elongation at break of both polymer blends decrease with presence of $\mathrm{CaCO}_{3}$. However, tensile strength of the composites of PE-g-AAc/EVA/CaCO 3 is higher than that of composites of $\mathrm{PE} / \mathrm{EVA} / \mathrm{CaCO}_{3}$. Beside that, the composites of PE-g-AAc/EVA/CaCO 3 have thermostability higher than the composites of $\mathrm{PE} / \mathrm{EVA} / \mathrm{CaCO}_{3}$.
\end{abstract}

Keywords: Polyethylene, ethylene-co-vinylacetate copolymer, calcium carbonate, polymer blend, composite, mechanical properties, morphology, thermostability.

\section{INTRODUCTION}

In recent years, study on composites formed by mixing polymers with additives or/and fillers is attracting many scientists due to their promising application in the living and technique fields. Many polymers are mixed with fine particles of the above substances to improve some properties of polymer matrix such as tensile strength, abrasion resistance, heat resistance, etc. Polymer blend based on polyethylene (PE) and ethylene-co-vinylacetate copolymer (EVA) has many good properties because it can combine advantages of both PE and EVA. Particularly, EVA has an ability of mixing with a large amout of fillers such as $\mathrm{CaCO}_{3}, \mathrm{Al}(\mathrm{OH})_{3}, \mathrm{Mg}(\mathrm{OH})_{2}$, clays to enhance some properties of polymer blend [1 - 5]. Because of difference of chemical structure between PE and EVA, PE is difficult to compatibilize with EVA. Modification of PE by grafting acrylic acid (AAc) onto PE can improve compatibility of PE with EVA.

This paper presents the results related to some properties and morphology of the composites formed by mixing polymer blend (unmodified- and modified PE/EVA) with $\mathrm{CaCO}_{3}$ activated by stearic acid in melt state. The experiemental results show that relative melt viscosity of the

\footnotetext{
* Corresponding author e-mail: thoang@ vnd.ncst.ac.vn
} 
polymer blend of PE/EVA is changed lightly with the presence of $\mathrm{CaCO}_{3}$. The tensile strength and elongation at break of the composite decrease with increasing content of $\mathrm{CaCO}_{3}$. However, these properties of the composites of PE-g-AAc/EVA/CaCO 3 are higher than those of the composites of $\mathrm{PE} / \mathrm{EVA} / \mathrm{CaCO}_{3}$ (in the same content of components). Grafting AAc onto PE enhances phase interaction, adhesion of $\mathrm{PE}$ with $\mathrm{EVA}$ and makes $\mathrm{CaCO}_{3}$ disperse more regularly into $\mathrm{PE}$ and EVA.

\section{EXPERIMENT}

\subsection{Chemicals and materials}

- Linear low density polyethylene (LLDPE) is supplied by Daelim Corporation (Korea) in grain form, density of $0.91 \mathrm{~g} / \mathrm{cm}^{3}$, melt index of $2.63-2.66 \mathrm{~g} / 10$ minutes $\left(190^{\circ} \mathrm{C}\right.$, weight load of $2.16 \mathrm{~kg}$ ), melt temperature of $120-125^{\circ} \mathrm{C}$.

- Copolymer ethylene - vinyl acetate (EVA) is Korean commercial product in grain form with vinyl acetate content of $18 \%$, melt temperature about $95-99^{\circ} \mathrm{C}$, density of $0.93 \mathrm{~g} / \mathrm{cm}^{3}$, melt index of $3.5 \mathrm{~g} / 10$ minutes $\left(190^{\circ} \mathrm{C}\right.$, weight load of $\left.2.16 \mathrm{~kg}\right)$.

- Acrylic acid (AAc) is Korean commercial chemical with density of $1.05 \mathrm{~g} / \mathrm{ml}$, boiling temperature about $140-142^{\circ} \mathrm{C}$.

- Dicumyl peroxide (DCP) supplied by Junsei Corporation (Japan).

- $\mathrm{KOH}$, xylene and toluene are Chinese industrial chemicals; 1,2 - dicloethane is Japanese commercial product.

- $\mathrm{CaCO}_{3}$ treated by $2 \%$ stearic acid was supplied by Hoang Lien Son Porcelain Company (Vietnam), in white powder form.

\subsection{Preparation of the composites of unmodified- and modified $\mathrm{PE} / \mathrm{EVA} / \mathrm{CaCO}_{3}$}

- Preparation of PE-g-AAc was carried out in a reactive extruder with L/D of 24. Content of AAc grafted onto PE determined by the method of titration with $\mathrm{KOH} / \mathrm{ethanol} 0.1 \mathrm{~N}$ is 0.67 wt.\% [6].

- The composites of unmodified- and modified $\mathrm{PE} / \mathrm{EVA} / \mathrm{CaCO}_{3}$ were prepared in the internal mixer Haake (German) connected to PolyLab 3.1 software to conduct the mixing process. The above components were mixed at $160^{\circ} \mathrm{C}$, mixing speed of $40 \mathrm{rpm}$ during 5 minutes. The composition ratio of PE/EVA and PE-g-AAc/EVA was 30/70 (wt./wt.) in all samples investigated.

\subsection{The experimental methods}

- Relative melt viscosity of the composites was expressed on the torque - mixing time diagrams of the mixture recorded by Polylab 3.1 software connected to Haake device.

- Morphology of the composites was observed on the scanning electron micrographs (SEM) taken by SEM - JEOL 5300 Instrument (Japan) with magnification of 1000 times.

- Mechanical properties of the composites were determined according to ASTM-D 638 - 84 with Universal ZWICK Instrument (Germany). 
- Thermostability of the composites was evaluated based on thermogravimetric analysis (TGA). The process of TGA was carried out with TA Instrument (Shimadzu DT 30A TGA) at a scanning rate of $10^{\circ} \mathrm{C} / \mathrm{min}$. in natural air.

\section{RESULTS AND DISCUSSION}

\subsection{Relative melt viscosity of the composites of PE-g-AAc/EVA/CaCO}

Relative melt viscosity of the composites is expressed by torque during mixing the components in the melt state. Diagram in figure 1 exhibits the dependence of torque on mixing time of polymer blend of PE-g-AAc/EVA (30/70) and the composites of PE-g-AAc/EVA/CaCO $\mathrm{CO}_{3}$ $(30 / 70 / 10)$ and $\mathrm{PE}-\mathrm{g}-\mathrm{AAc} / \mathrm{EVA} / \mathrm{CaCO}_{3}(30 / 70 / 20)$. It is clear that the presence of $\mathrm{CaCO}_{3}(10$ and $20 \mathrm{wt} \%$ ) does not make changes in the shape of the curves of torque - mixing time of polymer blend of PE-g-AAc/EVA. The shape of the curves is similar to that of polymer blend of PE/EVA (30/70) with and without $\mathrm{CaCO}_{3}$ (10 and 20 wt.\%).

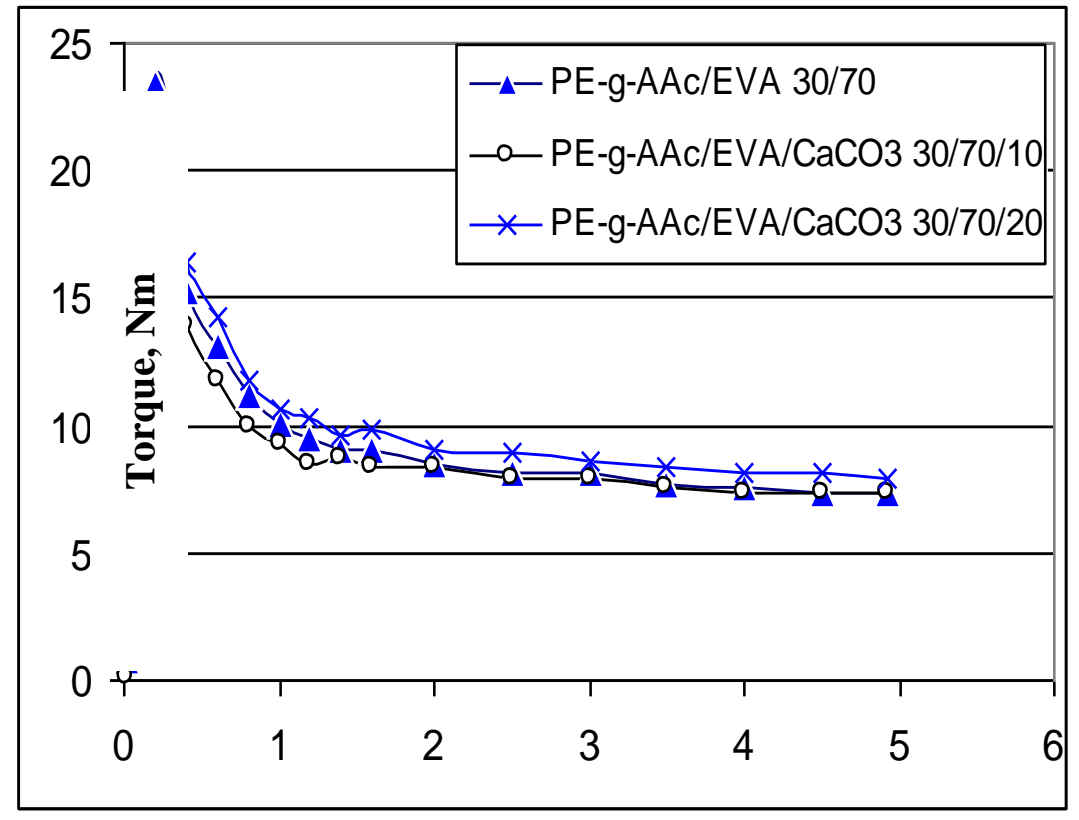

\section{Mixing time, minute}

Fig. 1: Diagram of torque - mixing time of PE-g-AAc/EVA (30/70), PE-g-AAc/EVA/CaCO (30/70/10) and PE-g-AAc/EVA/CaCO 3 (30/70/20).

Under the condition of high temperature and the rotate movement of the rotors, the polymers such as PE-g-AAc and EVA are melted and mixed with each other and $\mathrm{CaCO}_{3}$. The torque of mixtures reaches almostly constant value is called the stable torque. It is an important processing parameter. Table 1 shows that the stable torque of polyme blend of PE-g-AAc/EVA increases in presence of $\mathrm{CaCO}_{3}$. This is due to limitation of movement of polymer chains of PE, EVA by solid particles of $\mathrm{CaCO}_{3}$ in melt state. However, EVA has melt temperature and relative melt viscosity lower than PE-g-AAc, so the use of large amout of EVA (70 wt.\%) makes the mixtures melt easier and the components intermix each other advantagously. Therefore, the 
stable torque of composites only increase lightly with rising content of $\mathrm{CaCO}_{3}$. Preparation of the composites is carried out effectively at the investigated contents of $\mathrm{CaCO}_{3}$.

Table 1: Stable torque of the composites of PE-g-AAc/EVA (30/70) with different content of $\mathrm{CaCO}_{3}$.

\begin{tabular}{lccccc}
\hline Content of $\mathrm{CaCO}_{3}(\boldsymbol{w t . \%})$ & 0 & 5 & 10 & 15 & 20 \\
\hline Stable torque $(\mathrm{Nm})$ & 6.9 & 7.1 & 7.3 & 7.5 & 7.8 \\
\hline
\end{tabular}

\subsection{Morphology of the composites of unmodified- and modified $\mathrm{PE} / \mathrm{EVA} / \mathrm{CaCO}_{3}$}

In the Figs. $2 \mathrm{a}$ and $2 \mathrm{~b}$, the scanning electron micrographs (SEM) for polymer blend of PE/EVA and PE-g-AAc/EVA (in the same composition ratio of 30/70) indicate that grafting AAc onto PE improves dispersion of PE into EVA, PE dispreses into EVA more regularly with smaller size.

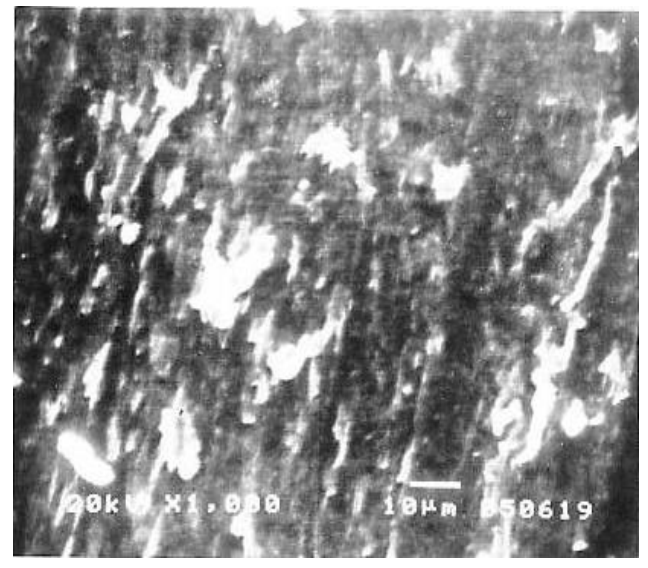

(a)

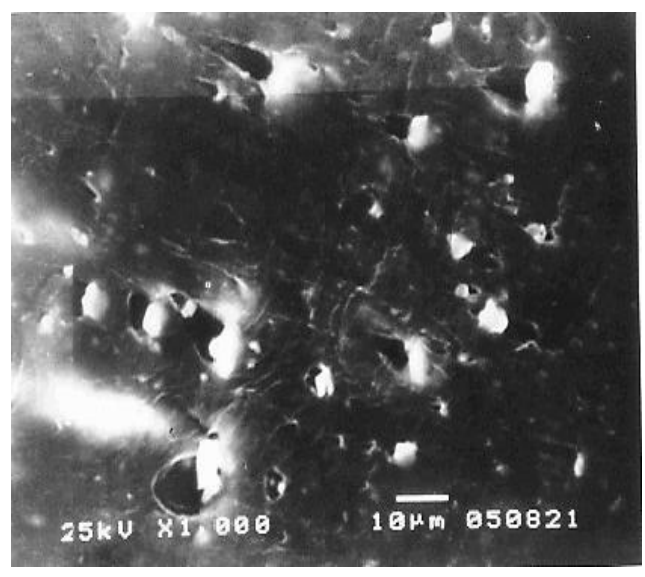

(c)

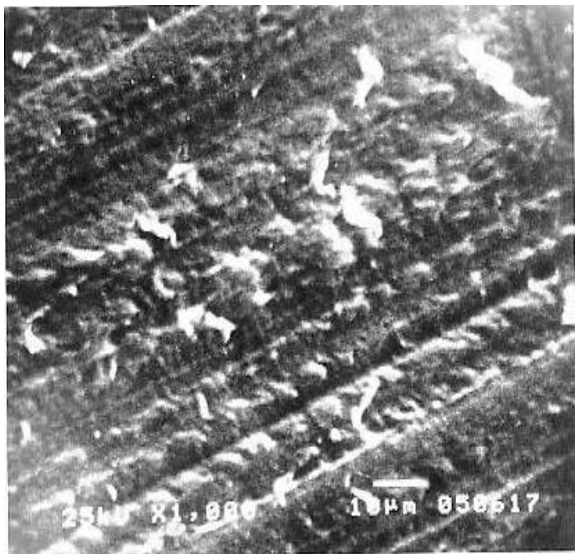

(b)

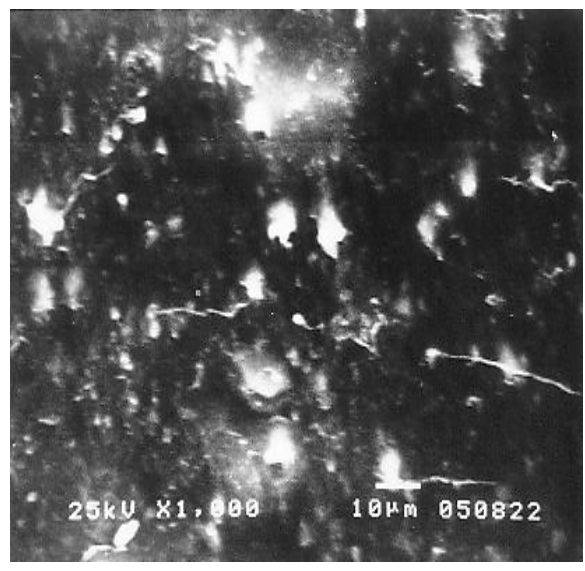

(d)

Fig. 2: Scanning electron micrograph (SEM) of PE/EVA (30/70) (a), PE-g-AAc/EVA (30/70) (b), PE/EVA/CaCO $3(30 / 70 / 20)($ c $)$ and $\mathrm{PE}-\mathrm{g}-\mathrm{AAc} / \mathrm{EVA} / \mathrm{CaCO}_{3}(30 / 70 / 20)(\boldsymbol{d})$. 
The SEM of the composites of PE/EVA/CaCO 3 (30/70/20) (Fig. 2c) shows that $\mathrm{CaCO}_{3}$ disperses into polymer blend of PE/EVA irregularly with large size $(5-22 \mu \mathrm{m})$ and surrounding $\mathrm{CaCO}_{3}$ particles, there are holes with diameter about $8-14 \mu \mathrm{m}$ in the polymer blend. That indicates the bad adhesion of the particles of $\mathrm{CaCO}_{3}$ with the polymer blend of PE/EVA. The SEM of the composites of PE-g-AAc/EVA/CaCO 3 (in the same composition ratio) demonstrates that the adhesion of the particles of $\mathrm{CaCO}_{3}$ and polymer blend of PE-g-AAc/EVA is improved (Fig. 2d). The particles of $\mathrm{CaCO}_{3}$ disperse into polymer blend of PE-g-AAc/EVA more regularly and with smaller size (about $3-10 \mu \mathrm{m}$ ). Surrounding these particles and in the polymer blend, the number and the size of holes decrease clearly. This may confirm that grafting AAc onto PE not only enhances the compatibility of PE with EVA but also improves adhesion of the particles of $\mathrm{CaCO}_{3}$ and the polymer blend.

\subsection{Mechanical properties of the composites of unmodified- and modified PE/EVA/CaCO}

Mechanical property of unmodified- and modified $\mathrm{PE} / \mathrm{EVA} / \mathrm{CaCO}_{3}$ composites in table 2 indicates that the presence of $\mathrm{CaCO}_{3}$ consideraly decrease in tensile strength and elongation at break of polymer blend of PE/EVA. This can be explained as follows: $\mathrm{CaCO}_{3}$ exists in inorganic mineral particles with large size (figure 2a). It prevents the compatibility of $\mathrm{PE}$ and EVA. On the other hand, the presence of particles of $\mathrm{CaCO}_{3}$ also rises the large holes because of the bad adhesion between these particles and polymer blend as mentioned above. In this case, the composites with some defects are easy to form [4,5,7]. Thus, tensile strength and and elongation at break of the composites of $\mathrm{PE} / \mathrm{EVA} / \mathrm{CaCO}_{3}$ are decreased.

Table 2: Tensile strength $(\sigma)$ and elongation at break $(\varepsilon)$ of the composites of unmodified-and modified PE/EVA/CaCO

\begin{tabular}{ccccc}
\hline \multirow{2}{*}{$\begin{array}{c}\text { Content of } \mathrm{CaCO}_{3} \\
(\text { wt.\%) }\end{array}$} & \multicolumn{2}{c}{ PE/EVA } & \multicolumn{2}{c}{ PE-g-AAc/EVA } \\
\cline { 2 - 5 } & $\boldsymbol{\sigma}(\mathbf{M P a})$ & $\boldsymbol{\varepsilon}(\boldsymbol{\%})$ & $\boldsymbol{\sigma}(\mathbf{M P a})$ & $\boldsymbol{\varepsilon}(\boldsymbol{\%})$ \\
\hline 0 & 15.18 & 775 & 17.08 & 668 \\
10 & 13.84 & 575 & 15.26 & 650 \\
15 & 13.41 & 575 & 15.28 & 650 \\
20 & 12.19 & 542 & 15.55 & 647 \\
\hline
\end{tabular}

Comparing with the composites of PE/EVA/CaCO exhibit the tensile strength with higher values at the same contents of $\mathrm{CaCO}_{3}$. Elongation at break of the composites of $\mathrm{PE} / \mathrm{EVA} / \mathrm{CaCO}_{3}$ is lower than that of the composites of PE-g$\mathrm{AAc} / \mathrm{EVA} / \mathrm{CaCO}_{3}$ at the contents of $\mathrm{CaCO}_{3}$. All above obtained results permit to confirm that grafting $\mathrm{AAc}$ onto $\mathrm{PE}$ is an important reason for improvement of tensile property of polymer blend of $\mathrm{PE} / \mathrm{EVA}$ reinforced by $\mathrm{CaCO}_{3}$.

\subsection{Thermostability of the composites of unmodified- and modified $\mathrm{PE} / \mathrm{EVA} / \mathrm{CaCO}_{3}$}

Figure 3 presents TG diagrams of the composites of PE/EVA/CaCO $3(30 / 70 / 20)$ and PE-g$\mathrm{AAc} / \mathrm{EVA} / \mathrm{CaCO}_{3}(30 / 70 / 20)$. The slope of the TG curve of the composite using PE-g-AAc is lower than that of the composite using unmodified PE. The initial decomposion temperature and weight loss at 300 and $350^{\circ} \mathrm{C}$ of the composites of unmodified- and modified PE/EVA/CaCO are performanced in table 3 . 


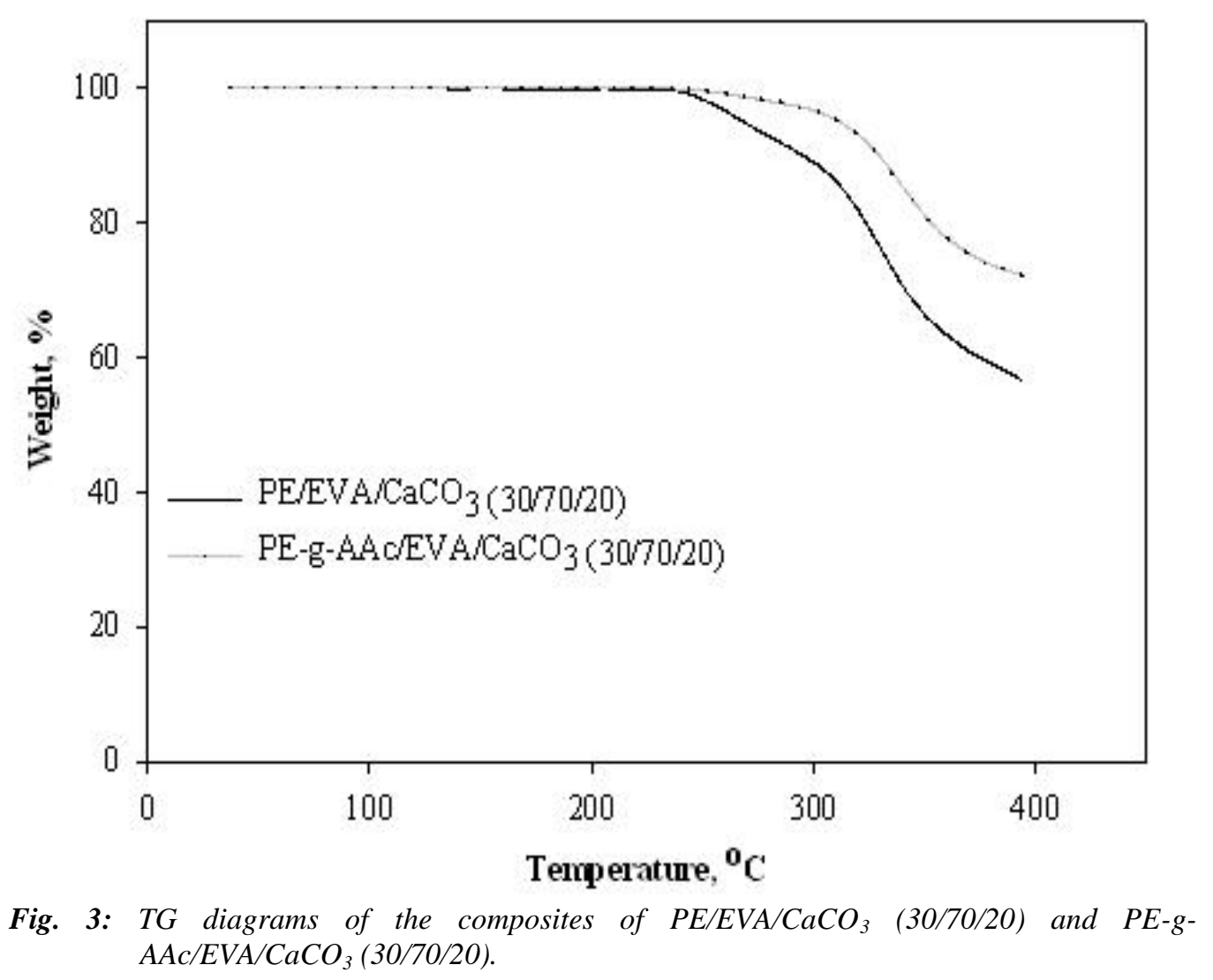

Table 3: TG data of the composites of unmodified- and modified PE/EVA/CaCO $\mathrm{C}_{3}$.

\begin{tabular}{lccc}
\hline \multirow{2}{*}{ Sample } & $\begin{array}{c}\text { Initial decomposition } \\
\text { temperature }\left({ }^{\circ} \mathbf{C}\right)\end{array}$ & \multicolumn{2}{c}{ Weight loss (\%) at } \\
\cline { 3 - 4 } & 230.0 & $\mathbf{3 0 0}^{\circ} \mathbf{C}$ & $\mathbf{3 5 0}^{\circ} \mathbf{C}$ \\
\hline PE/EVA (30/70) & 230.7 & 11.23 & 35.06 \\
$\mathrm{PE} / \mathrm{EVA} / \mathrm{CaCO}_{3}(30 / 70 / 20)$ & 231.5 & 10.96 & 33.79 \\
$\mathrm{PE}-\mathrm{g}-\mathrm{AAc} / \mathrm{EVA}(30 / 70)$ & 232.4 & 9.14 & 20.35 \\
$\mathrm{PE}-\mathrm{g}-\mathrm{AAc} / \mathrm{EVA} / \mathrm{CaCO}_{3}(30 / 70 / 20)$ & & 3.30 & 19.09 \\
\hline
\end{tabular}

The TG data in table 3 expresses that grafting AAc onto PE enhances thermostability not only for polymer blend of PE/EVA but also for the composites of $\mathrm{PE} / \mathrm{EVA} / \mathrm{CaCO}_{3}$. The addition of $\mathrm{CaCO}_{3}$ into polymer blends also makes the materials become more thermostable. The composite of $\mathrm{PE}-\mathrm{g}-\mathrm{AAc} / \mathrm{EVA} / \mathrm{CaCO}_{3}(30 / 70 / 20)$ has thermostability higher than the composite of $\mathrm{PE} / \mathrm{EVA} / \mathrm{CaCO}_{3}(30 / 70 / 20)$. The initial decomposition temperature of the composite using PEg-AAc is higher than that of the composite using unmodified PE. The weight loss at the same temperature of the composite of $\mathrm{PE}-\mathrm{g}-\mathrm{AAc} / \mathrm{EVA} / \mathrm{CaCO}_{3}$ is clearly lower than that of the composite of $\mathrm{PE} / \mathrm{EVA} / \mathrm{CaCO}_{3}$. This can be explained by interfacial adhesion of the particles of 360 
$\mathrm{CaCO}_{3}$ and polymer blend of PE-g-AAc/EVA is better than that of the particles of $\mathrm{CaCO}_{3}$ and polymer blend of PE/EVA. Therefore, the structure of the composite of PE-g-AAc/EVA/CaCO 3 becomes closer and more regularly. This structure is able to prevent permeation of oxygen, so reduces the thermal oxidation degradation of the composite.

\section{CONCLUSION}

a. The presence of $\mathrm{CaCO}_{3}(10$ and $20 \mathrm{wt} . \%)$ changes lightly stable torque of polymer blend of PE-g-AAc/EVA.

b. Interfacial adhesion and dispersion of the particles of $\mathrm{CaCO}_{3}$ into polymer blend of PE-g$\mathrm{AAc} / \mathrm{EVA}$ are better than those of particles of $\mathrm{CaCO}_{3}$ into polymer blend of PE/EVA.

c. Tensile strength of the composites of PE-g-AAc/EVA/CaCO 3 is higher than that of the composites of $\mathrm{PE} / \mathrm{EVA} / \mathrm{CaCO}_{3}$.

d. The composite of PE-g-AAc/EVA/CaCO 3 has thermostability higher than the composite of $\mathrm{PE} / \mathrm{EVA} / \mathrm{CaCO}_{3}$.

\section{ACKNOWLEDGEMENT}

This work was supported by the Natural Science Council of Vietnam in the period of 2004 2005.

\section{REFERENCES}

1. Mitsuishi, K. (1997), J. Appl. Polym. Sci., Vol. 9(6), pp. 434-441.

2. Chuanxi Xiong, Shengjun Lu, Dongyan Wang, Lijie Dong, David D. Jiang, and Qinggang Wang (2005), Nanotechnology, 16, pp. 1787-1792.

3. Yong Wang, Jin Lu, Guiheng Wang (1998), J. Appl. Polym. Sci., 64(7), pp. 1275-1281.

4. Mitsuishi, K., Kodama, S., Kawasaki, H., Tanaka, M., and Kobunshi Ronbunshu (1972), J. Appl. Phys., 43, p. 2235.

5. Mustafa Oksuz and Huseyin Yldrm (2005), J. Appl. Polym. Sci., Vol. 96(4), pp. 1126-1137.

6. Thai Hoang, Nguyen Vu Giang, Trinh Son Ha, Do Quoc Manh (2003), Vietnamese Journal of Chemistry, 41( 2), pp. 16-22.

7. Hale, M.R., MeGuire, J., Sand, I.D., and Dohrer, K.K. (2001), J. Appl. Polym. Sci., Vol. 82(10), pp. 2454-2471.

8. Thai Hoang and Do Van Cong (2005), Vietnamese Journal of Chemistry (accepted). 